\title{
Knowledge of and Attitude Toward AIDS Among Turkish University Students in Izmir
}

\section{Ibrahim Yakin 1,", Nuran Aydemir ${ }^{2}$}

${ }^{1}$ Health and Social Psychology, Master of Art, Social Sciences, Kadir Has University, Fatih/Istanbul.

${ }^{2}$ Department of Psychology, Istanbul University.

*Corresponding Author: Ibrahim Yakin, Health and Social Psychology, Master of Art, Social Sciences, Kadir Has University. Fatih/Istanbul

Received date: 01 December 2020; Accepted date: 15 February 2021; Published date: 20 February 2021

Citation: Yakin I, Aydemir N. Knowledge of and Attitude Toward AIDS among Turkish University Students in Izmir. J Comm Med and Pub Health Rep 2(1): https://doi.org/10.38207/jcmphr20210004

Copyright: (C) 2021 Ibrahim Yakin. This is an open-access article distributed under the terms of the Creative Commons Attribution License, which permits unrestricted use, distribution, and reproduction in any medium, provided the original author and source are credited.

\begin{abstract}
HIV+/AIDS is still an important health issue and continues to infect especially young adults in Turkey. The present study aims to investigate the knowledge of and attitudes toward AIDS among university students, and to determine variables explaining higher knowledge and a better attitude in Turkish university students. AIDS-knowledge and AIDS-attitude scale which is developed for the Turkish culture was applied to 1402 university students in Izmir. Descriptive statistics and logistic regression were used. The mean age was 20.9 \pm 2.66 . Almost a fourth of the participants $(63.1 \%)$ were female. Descriptive results showed that $38.9 \%$ of the sample had sexual intercourse and the mean age for the first sexual experience was $18 \pm 2.32 .76 .6 \%$ read something about AIDS. Only $43.4 \%$ of the participants had a higher level of knowledge about AIDS, whereas $46.5 \%$ had favorable attitudes towards AIDS. Logistic regression models revelated that (1) having not a religious belief, higher income, and has read something about AIDS increased the likelihood of being more knowledgeable. (2) Being a woman, having not a religious belief has tested STIs before, and has higher knowledge increased the likelihood of a positive attitude toward AIDS. University students in Izmir have moderate knowledge about AIDS, especially about the treatment aspects. However, their attitudes are more favorable compared to their amount of knowledge. Intervention programs aimed to increase knowledge about AIDS and change the attitude toward it should consider the effects of religiosity which is significantly associated with both knowledge of and attitude toward AIDS.
\end{abstract}

Keywords: AIDS/HIV, knowledge, attitude, university students.

\section{Introduction}

Human Immunodeficiency Virus (HIV) is a viral agent in the retrovirus group that targets the helper T cells and macrophages of the immune system. It is mostly transmitted via the exchange of certain bodily fluids, especially blood and semen [1]. The immune system deficiency caused by HIV is known as Acquired Immunodeficiency Syndrome (AIDS). Although the number of new cases has been decreasing, the total number of people living with HIV reached 36.9 million individuals [2]. The treatment gap in AIDS still exists; only three out of four people living with HIV are aware of their status According to the latest records, 21.7 million people are on treatment [2]. In Turkey, based on the Turkish Ministry of Health records as of January 31, 2019, Turkey has 12.992 HIV+ individuals in total, and 591 individuals with AIDS [3]. Till January 31, 2019, one hundred and nine individuals died because of AIDS. The age range with the highest numbers of AIDS cases is between 30-34 with 286 individuals, between 35-39 with 284 individuals [3]. Based on these statistics, it could be claimed that young adults are more vulnerable to contracting HIV than any other age group in Turkey. Therefore, it is important to disseminate correct information about the ways of transmission and ways of protection from HIV and other STIs (sexually transmitted infections) among young adults in Turkey.Also, like the other sexually transmitted infections, contracting HIV is always related to behavior, hence contracting HIV is preventable with protective health behaviors, such as always using condoms. Accordingly, it is also quite important to collect information about protective health behaviors and their level of awareness. Thus, the first aim of the present study was to examine the knowledge level of AIDS among young adults in Turkey.

Another important point that we would like to address is stigma. Since stigma and discrimination are still prevalent in HIV and AIDS $[\mathbf{2}, \mathbf{4 , 5}]$, it is also important to assess the attitudes of young adults toward them. Additionally, increased knowledge about HIV/AIDS is usually correlated with positive attitudes toward HIV/AIDS [6,7,8,9] [10]. Therefore, the second aim of the present study was to examine the attitudes toward AIDS. Previous studies indicate that socioeconomic status (SES) $[\mathbf{1 1}, 12]$, and gender $[11,13,14]$ can cause differences in knowledge about HIV/AIDS and attitude toward them. Therefore, income and gender were also included as predicting variables in the present study. Also, some studies [15,16] show the role of religiosity on attitudes and stigma toward people with HIV/AIDS. Since almost $97 \%$ of the population in Turkey stated themselves as believers in God [17], it is worth investigating how this reflects itself into the attitudes toward AIDS. Therefore, the level of religiosity was also included as a predicting variable. There have been previous attempts 
to assess the level of knowledge and attitude toward AIDS/HIV in Turkey, such that there were some studies conducted on nursing students, on students from different health-related departments $[18,19,20]$ and on university students from non-health-related departments $[\mathbf{2 1}, \mathbf{2 2}, \mathbf{2 3}]$. However, in none of these previous studies, scales developed and psychometrically tested for the Turkish

\section{Methods}

\section{Study Design and Sample}

In this current cross-sectional study, 1402 university students who were enrolled in five different universities in Izmir were included in the current study by using the convenience sampling method. During data collection, first, it was approached to different course instructors from different universities and they were informed about the study. If the instructors gave permission, the researchers entered their courses at the end or at the beginning of the course sessions. Then, the students were informed about the study. If the students agreed to participate, it

\section{Instruments}

Demographic information form: This form includes questions about participants' gender, age, income level, religiosity, the experience of sexual intercourse, condom use, and frequency of condom use, and familiarity with AIDS.

AIDS Knowledge Scale: AIDS Knowledge and Attitude The scale was developed specifically for the Turkish culture [9]. AIDS knowledge scale measures knowledge about the ways of transmission and protection from HIV and treatment of AIDS [9]. It comprises 21 items covering three factors: (1) ways of transmission, 7 items, e.g.,

\section{AIDS Attitude Scale:}

AIDS Attitude Scale was also developed specifically for the Turkishculture. This scale contains 17 items which aim to assess lay people' sattitudes toward AIDS and individuals with AIDS [9]. The scale has a two-factor structure: (1) stigma, 5 items, e.g., Having AIDS is something to be ashamed about, and (2) negative attitude toward contacts with people with AIDS, 12 items, e.g., I would date a personwith AIDS. Scores on the Attitude

\section{Data Analysis}

Data was analyzed in SPSS 25.0. Descriptive statistics were used to determine the socio-demographic characteristics of the participants. Binary logistic regression was used to examine the predictors of knowledge and attitude. Median values were used as cut-off points

\section{Results}

More than half of the participants were female $(63.1 \%)$. The age range of the participants varied between 17 and 54 years $(M=20.9$, $\mathrm{SD}=2.66)$. Most of the participants $(93.6 \%)$ were between ages 17 to 24 . A huge percent $(87.7 \%$ ) was grown up in urban. More than half of the participants $(59.6 \%)$ were enrolled in state universities. In population was applied. Therefore, the aims of this present study were: (1) to assess to the knowledge of, and attitude toward AIDS among Turkish university students; and (2) to determine variables that explain higher knowledge and the better attitude in Turkish university students.

was asked to fill out the demographic information form, AIDS knowledge, and AIDS attitude scale. The completion of the whole scales took approximately 15 minutes. In order to protect the anonymity of the participants, no identity information was asked. The data collection procedure started in the spring and fall semester of 2016-2017 and continued through the fall semester of 2017-2018. The study was approved by the Ethics Committee of Izmir University of Economics (No: B.30.2. İEU.0.05-020-048).

Eating from the same plate with a person with AIDS can transmit the infection; (2) ways of protection, 9 items, e.g., Monogamy can be helpful in protecting against AIDS; and (3) treatment, 5 items, e.g., There is a vaccine for AIDS. The AIDS Knowledge Scale's Kuder Richardson-20 internal consistency coefficient was 0.76. The response options of the knowledge scale are true ( 1 point), false ( 0 point), and not sure (0 points). High scores represent more knowledge about AIDS.

Scale range from 1 (completely disagree) to 5 (completely agree). Higher scores represent a more positive attitude toward AIDS and individuals with AIDS. AIDS Attitude Scale's Cronbach's Alpha value was found as 0.90 .

for both knowledge and attitude scores to create an outcome variable. Participants who were above the median value coded as the outcome variable, that represents participants with higher knowledge and participants with more positive attitudes.

terms of income level, the highest reported group was middle income $(43.5 \%)$. The majority of the participants had religious beliefs (78.1 $\%)$. All demographic information of the participants was summarized in (Table. 1). The descriptive results showed that $38.9 \%$ of the sample have had sexual intercourse. The mean age for the first sexual 
experience was $18(\mathrm{SD}=2.32)$. While $31.8 \%$ of the students reported using condoms "usually", $26.4 \%$ of them reported their usage frequency as "always". It was also revealed that $6.7 \%$ of the participants have been tested forSTIs, and only $4 \%$ of them had been tested for HIV. Almost all of the participants $(98.4 \%)$ had heard about AIDS, $77.1 \%$ had read something about AIDS and only $3.6 \%$ know someone with AIDS

Table 1. Demographic characteristics of the participants

\begin{tabular}{|l|l|}
\hline Variables & Percentage (\%) \\
\hline Gender & 36.9 \\
\hline Male & 63.1 \\
\hline Female & \\
\hline Age & 93.6 \\
\hline $17-24$ & 5.3 \\
\hline $25-30$ & 0.9 \\
\hline $31-40$ & 0.2 \\
\hline $40-54$ & \\
\hline Place of Growing & 12.3 \\
\hline Rural background & 87.7 \\
\hline Urban background & \\
\hline Type of University & 40.4 \\
\hline Private & 59.6 \\
\hline State & \\
\hline Income Level & 33.6 \\
\hline Low (0 - 1386 TL) & 43.7 \\
\hline Moderate (1387 - 4515) & 22.6 \\
\hline High (4516 TL >) & \\
\hline
\end{tabular}

\section{Knowledge about AIDS}

The descriptive results of the knowledge scales were shown in (Table. 2). Although the highest score in the knowledge scale was 21, the mean score of participants was $12.6(\mathrm{SD}=4.21)$, and only $43.4 \%$ of the participants got higher scores from the median values. Also,
$47.5 \%$ of the participants got higher score from the protection subscale, $42.1 \%$ of the participants from the ways of transmission subscale and $39 \%$ got higher scores from the treatment subscale.

Table 2. Descriptive results of the AIDS knowledge and AIDS attitude scale.

\begin{tabular}{|l|l|l|l|l|l|l|l|}
\hline Outcomes & $\mathbf{N}$ & $\mathbf{X}$ & $\mathbf{S D}$ & $\mathbf{M i n}$. & $\mathbf{M a x}$. & Median & a High Score (\%) \\
\hline Total Knowledge Score & 1331 & 12.63 & 4.14 & .00 & 21 & 13 & 43.4 \\
\hline Ways of Transmission & 1369 & 3.62 & 2.45 & .00 & 7 & 4 & 41.1 \\
\hline Ways of Protection & 1367 & 6.11 & 2.05 & .00 & 9 & 6 & 47.5 \\
\hline Treatment & 1386 & 2.90 & 1.48 & .00 & 5 & 3 & 39.0 \\
\hline Total Attitude Score & 1340 & 56.05 & 11.54 & 21 & 85 & 57 & 49.9 \\
\hline Stigma & 1370 & 18.93 & 3.90 & 5 & 25 & 19 & 48.4 \\
\hline Negative Attitude Toward Contact with People with AIDS & 1345 & 37.11 & 9.29 & 12 & 60 & 38 & 46.5 \\
\hline
\end{tabular}

Note: ${ }^{a}$ The median value was used as a cut-off point to determine high scores.

Binary logistic regression was used to determine the predictors of having higher knowledge about AIDS. Model 1 was performed to test the effect of gender, religiosity, income level, the experience of sexual intercourse, whether being tested for STIs before, whether read something about AIDS before on general knowledge. Model 1 was statistically significant $\left[\chi^{2}(6, \mathrm{~N}=1155)=51.523, \mathrm{p}<0.01\right]$. The model had a good fit to the data $\mathrm{p}=0.716(>0.05)$. Model 1 classified correctly $59.5 \%$ of cases $(77.1 \%$ in the lower knowledge, $36.3 \%$ in the higher knowledge, $\mathrm{R}^{2}=0.06$ ). Results showed that not having a religious belief $[\mathrm{OR}=1.65,95 \% \mathrm{CI}(1.23,2.22)]$, increase in income 
$[\mathrm{OR}=1.22,95 \% \mathrm{CI}(1.04,1.43)]$, and have been read something about AIDS [OR $=0.48,95 \% \mathrm{CI}(0.35,0.64)]$ were associated with an increased likelihood of having higher knowledge about AIDS.
However, gender, previously being tested for STIs, and the experience of sexual intercourse was not associated with knowledge of AIDS (Table 3).

Table 3: Logistic Regression Results of Knowledge of AIDS

\begin{tabular}{|l|l|l|l|l|}
\hline & $\boldsymbol{\beta}$ & $\mathbf{p}$ & OR & CI 95\% \\
\hline Gender & -.19 & 0.142 & 0.83 & $0.64,1.07$ \\
\hline Religious Belief & $\mathbf{. 5 0}$ & 0.001 & 1.65 & $1.22,2.22$ \\
\hline Income & $\mathbf{. 2 0}$ & 0.017 & 1.21 & $1.04,1.43$ \\
\hline Experience in Sexual Intercourse & -.10 & 0.494 & 0.91 & $0.69,1.20$ \\
\hline Have STIs Test or not & & & & \\
\hline Have read something about AIDS or not & -.18 & 0.475 & 0.84 & $0.51,1.36$ \\
\hline
\end{tabular}

Note: Nagelkerke $\mathrm{R}^{2}$ of this logistic model was 0.06

\section{Attitude toward AIDS}

The descriptive results of the attitude scales were shown in (Table 2). Although the highest score in the knowledge scale was 85 , the mean score of participants was $56.1(\mathrm{SD}=4.21)$, and only $49.9 \%$ of the participants received a higher score. For the negative attitude toward contact with people with AIDS subscale $46.5 \%$ of the participants, and for the stigma subscale $48.4 \%$ got higher scores. Binary logistic analysis was used to investigate the predictors of having more positive attitude toward AIDS. The predictor variables were gender, religiosity, income level, the experience of sexual intercourse, had been tested for STIs, and the total knowledge score. Model 2 was statistically significant $[\chi 2(6, N=1114)=70.459, \mathrm{p}<0.01]$. It had a good fit to the data $\mathrm{p}=0.677$ ( $>0.05)$. Model 2 classified correctly $61.1 \%$ of cases $(70.1 \%$ in having lower attitude, $51.9 \%$ in having higher attitude, $\mathrm{R}^{2}=0.08$ ). Results showed that being woman $[\mathrm{OR}=$ $0.54,95 \% \mathrm{CI}(0.41,0.70)]$, having no religiousbelief [OR $=2.15,95$ $\% \mathrm{CI}(1.57,2.95)]$, being tested for STIs before $[\mathrm{OR}=0.54,95 \% \mathrm{CI}$ $(0.31,0.91)]$, and being more knowledgeable about AIDS [OR = 1.60, $95 \%$ CI $(1.25,2.05)]$ were associated with increased likelihood of having more positive attitude toward AIDS. Income and experience of sexual intercourse were not related to attitude (Table 4).

Table 4. Logistic Regression Results of Attitude toward AIDS

\begin{tabular}{|l|l|l|l|l|}
\hline & \multicolumn{4}{|l|}{ Attitude toward AIDS } \\
\hline Predictors & $\mathbf{B}$ & $\mathbf{p}$ & OR & CI 95\% \\
\hline Gender & -.62 & 0.000 & 0.54 & $0.41, .70$ \\
\hline Religious Belief & $\mathbf{0 . 7 7}$ & 0.000 & 2.15 & $1.57,2.95$ \\
\hline Income & -.09 & 0.296 & 0.92 & $0.78,1.08$ \\
\hline Experience in Sexual Intercourse & -.06 & 0.924 & 0.94 & $0.71,1.25$ \\
\hline Have STIs Test or not & & & & \\
\hline Knowledge of AIDS & -.63 & 0.031 & 0.55 & $0.31, .91$ \\
\hline
\end{tabular}

Note: Nagelkerke $\mathrm{R}^{2}$ of these logistic models was .08 in attitude toward AIDS.

\section{Discussion}

In the current study, we investigated the knowledge of and attitude toward AIDS and the variables that predict them among Turkish university students studying in Izmir. Parallel to previous studies from Turkey and across the world [11,22,23,24], nearly all of the participants had heard about HIV/AIDS and about two-third of the participants had read about AIDS. However, almost none of the participants had been tested for HIV and only one-third of the participants usually use condoms. When it was compared to previous studies $[\mathbf{2 5 , 2 6 ]}$ in terms of condom use, Turkish university students' ratio is somewhere in between. Also, being tested for HIV is lower than Iran [26], which is one of Turkey's neighboring countries. Based on these results, it can be assumed that, although the participants received some information about HIV and AIDS, this information does not reflect itself onto behavior that makes them vulnerable to contracting HIV and other STIs. The amount of knowledge of AIDS could be evaluated as below moderate, especially in items related to 
transmission and treatment. The number of participants who have higher knowledge about AIDS was similar to the university students in the United Arab Emirates [27] and in Yemen [28]. The participants' knowledge about ways of protection was higher than the ways of transmission, and it is at the lowest level in the treatment aspects of AIDS. This finding is similar to Iran [26]. However, the participants' general attitude toward AIDS was more favorable compared to their knowledge level. Furthermore, knowledge was a significant predictor of attitude. Participants with more knowledge of AIDS showed a more positive attitude toward it which is in concordance with previous studies [25]. Also, students who read about AIDS had higher knowledge about it. Therefore, efforts to disseminate correct knowledge related to STIs seem to be quite important in this matter. Having STIs test was not related to the knowledge of AIDS, but it had an effect on the attitude toward AIDS. Students who had been tested for STIs showed a more positive attitude toward AIDS. Additionally, the experience of sexual intercourse had an effect neither on knowledge nor on attitude toward AIDS. It was also found that woman have more favorable attitudes toward AIDS than males, while gender had no effect on knowledge. These findings are inconcordance with previous studies that showed women have more positive attitude and less stigma toward AIDS [26], however, genderhas no effect on knowledge [27].

In terms of religiosity, our findings indicate that when no religious belief was stated, the participants' attitude toward AIDS become more positive, and furthermore, they become more knowledgeable. This finding is similar to a study from the USA that aimed to investigate the relationship between HIV stigma and religiosity in African American Women [29]. In that study, it was found that participants who had less knowledge about HIV/AIDS had a higher religious stigma toward HIV/AIDS. However, contrary to our findings

\section{Conclusion}

This is the first study in Turkey that assess knowledge of and attitude towards AIDS, and the variables that predict both knowledge and attitude. Results showed that university students in Izmir have moderate knowledge about AIDS, especially about the treatment aspects of AIDS, but have relatively favorable attitudes toward people Acknowledgments: This study was not financially supported.

\section{References}

1. Taylor SS. Health Psychology ( $7^{\text {th }}$ Eds.). McGraw Hill, 2009.

2. Data Report. UNAIDS. Data 2017 Report.

3. Turkish Ministry of Health (2019), General Director of Public Health. Statistics of HIV - AIDS, Ankara.

4. Fernandes PT, Salgado PC, Noronha AL, Barbosa F, Souza
Norman, Carr, and Jiménez [16] found that students with high spirituality express more sympathy toward people with HIV. In a study conducted in Saudi Arabia which constitutes only male college students, religiosity was found to be related neither to knowledge nor to stigma [10]. In that study, AIDS-related shame was found as the best predictor of AIDS stigma. In another study from Malaysia, although participants had a high level of AIDS-related knowledge, they still had moderate levels of self and public stigma. The author speculated that the religious belief that evaluates HIV/AIDS as immoral could be the reason why higher knowledge does not affect the self-stigma [12]. Contradictions among the results related to religiosity and negative attitude or stigma in the literature point out the need for further studies. Another important aspect based on this result is that any intervention study that aims to target the attitude toward AIDS and any other STIs, should consider the importance of religious values and therefore the culture [30]. The results for the income showed that only the knowledge was predicted by the income level. There were a few previous studies $[\mathbf{1 1}, \mathbf{1 2}, \mathbf{3 1}]$ which examined the effect of income on knowledge and attitude/stigma. Parallel to our findings in a study conducted in Malaysia, household income predicted both HIV-transmission knowledge and discriminatory attitudes toward people with HIV/AIDS [12]. In that study, people with high SES found to have less discriminatory social attitudes toward people with HIV/AIDS. The present study has some limitations. The primary limitation of the current study is the use of the convenience sampling method. Although participants were recruited from different universities in Izmir to increase the representativeness of the sample, it cannot be claimed that our results represent the university student population either in Izmir or in Turkey. Second, since this study is a correlational study, it is not possible to draw any causality based on the results.

with AIDS. Knowledge was predicted by religiosity, income, and familiarity with AIDS. However, the attitude was predicted by gender, religiosity, being tested for STIs, and the experience of sexual intercourse.

Declaration of Conflict of Interest: We did not have any conflicts of interest for the research authorshipand publication of this article.

E.A.P, et al. (2007) Prejudice towards chronic diseases: Comparison among epilepsy, AIDS, and diabetes. Seizure.16(4):320-323.

5. Kasapoğlu A, Kus, E (2008) The role of gender in testigmatization of people living with HIV/AIDS in Turkey. Journalof Gender Studies. 17(4): 359-368. 
6. Iliyasu Z, Abubakar IS, Kabir M, Aliyu MH (2006)

Knowledge of HIV/AIDS and attitude towards voluntary counseling andtesting among adults. J Natl Med Assoc. 98(12): 1917-1922.

7. Chao L.W, Gow J, Akintola G, Pauly M (2010) HIV/AIDS Stigma Attitudes Among Educators in KwaZulu-Natal. J Sch Health. 80(11): 561-569.

8. Dawson LJ, Chunis ML, Smith DM, Carboni AA (2001) The roleof academic discipline and gender in high school teachers' AIDS-related knowledge and attitudes. Journal of School Health. 71(1):3-8.

9. Aydemir N, Yakin I, \& Arslan HS (2018) Developing AIDS Knowledge and AIDS Attitude Scales and Assessing their Reliability and Validity. Studies in Psychology. 38(1): 73-93.

10. Badahdah AM (2010) Stigmatization of persons with HIV/AIDSin Saudi Arabia. Journal of Transcultural Nursing. 21(4): 386- 392.

11. Gokengin D, Yamazhan T, Ozkaya D, Aytug ${ }^{`} \mathrm{~S}$, Ertem E et al.(2003) Sexual knowledge, attitudes, and risk behaviors of students in Turkey. Journal of School Health. 73(7): 258263.

12. Wong LP (2013) Prevalence and factors associated with HIV/AIDS- related stigma and discriminatory attitudes: A cross-sectional nationwide study. Preventive Medicine. 57(1): 60-63.

13. Gańczak M, Barss P, Alfaresi F, Almazrouei S, Muraddad A, et al. (2007) Break the silence: HIV/AIDS knowledge, attitudes, andeducational needs among Arab university students in United ArabEmirates. J Adolesc Health. 40(6): 572-578.

14. Petro-Nustas W (2000) University students' knowledge of AIDS.International Journal of Nursing Studies. 37(5): 423433.

15. Genrich GL, Brathwaite BA (2005) Response of religious groupsto HIV/AIDS as a sexually transmitted infection in Trinidad. BMC Public Health. 5: 121-143.

16. Norman LR, Carr R, Jimenez J (2007) Sexual stigma, and sympathy: Attitudes toward persons living with HIV in Jamaica. Cul Health \& Sex. 8(5): 423-433.

17. KONDA. In this case, it is possible to use a turbine and a turbine.

18. Akin S, Mendi B, Mendi O, Durna Z (2013) Turkish nursing students' knowledge of and attitudes towards patients with HIV/AIDS. Journal of Clinical Nursing. 22(23-24); 33613371.

19. Turhan O, Senol Y, Baykul T, Saba R, Yalçın AN (2010) Knowledge, attitudes and behavior of students from a medicine faculty, dentistry faculty, and medical technology VocationalTraining School toward HIV/AIDS. International
Journal of Occupational Medicine and Environmental Health. 23(2): 153-160.

20. Toker SO, Kuçukyilmaz U (2001) Evaluation of HIV/AIDS knowledge level of the students of Ege University Odemiş healthschool before and after education. Ege J Med. 40(2): 91-97.

21. Avcikurt AS. Evaluation of knowledge and attitudes on HIV/AIDS of Balikesir University student. Balikesir Health Sciences Journal. 2014; 3(2): 81-86.

22. Cok F, Gray LA, Ersever H (2001) Turkish university students' sexual behavior, knowledge, attitudes, and perceptions of risk related to HIV/AIDS. Culture, Health \& Sexuality. 3(1): 81-99.

23. Yazganoglu KD, Ozarmagan G, Tozeren A, Ozgulnar N (2012) Knowledge, behavior, and attitudes of university students towardsexually transmitted infections. Journal of Turkderm Archives ofthe Turkish Dermatology. 46(1): 2025.

24. King KA, Vidourek RA, Singh A (2014) Condoms, sex, and sexually transmitted diseases: Exploring sexual health issues among Asian-Indian college students. Sexuality \& culture. 18(3):649-663.

25. Thanavanh B, Harun-Or-Rashid MD, Kasuya H, Sakamoto J (2013) Knowledge, attitudes, and practices regarding HIV/AIDSamong male high school students in Lao People's Democratic Republic. J Int AIDS Soc. 16 (1): 17387.

26. Shokoohi M, Karamouzian M, Mirzazadeh A, Hangdoost A, Rafierad A-A, et al. (2016) HIV knowledge, attitudes, and practices of young people in Iran: Findings of a national population-based survey in 2013 PLOS One 11(9).

27. Haroun D, El Saleh O, Wood L, Mechli R, Al Marzouqi N, et al.(2016) Assessing knowledge of, and attitudes to, HIV/AIDSamong university students in the United Arab Emirates. PLOS One 11(2).

28. Babadahdah AM, Sayem N (2010) HIV-related knowledge and AIDS stigma among college students in Yemen. EMHJEastern Mediterranean Health Journal. 16 (8): 901-906.

29. Maturi N, An S. (2010) HIV/AIDS stigma and religiosity amongAfrican American women. J Health Commu 15 (4): $388-401$.

30. Airhihenbuwa CO, Ford CL, Iwelunmor JI (2014) Why culture matters in health interventions: Lessons from HIV/AIDS stigma and NCDs. Health Edu \& Behav. 41 (1): 78-84.

31. Kobeissi L, El Kak FH, Khawaja M, Khoshnood K 2015 HIV/AIDS-related knowledge and its association with socioeconomic status among women: Results of Lebanese survey for family health (PAPFAM) 2004. Asia-Pacific Journal of Public Health. 27(2): 734-745. 